\title{
Selective Antegrade Cerebral Perfusion Attenuating the TLR4/NF-KB Pathway during Deep Hypothermia Circulatory Arrest in a Pig Model
}

\author{
Zhi-Xian Tang ${ }^{\mathrm{a}}$ Guang-Xian Chen ${ }^{\mathrm{a}}$ Meng-Ya Liang ${ }^{\mathrm{a}}$ Jian Rong ${ }^{\mathrm{b}}$ \\ Jian-ping Yao ${ }^{a}$ Xiao Yang $^{a}$ Zhong-Kai Wu ${ }^{a}$ \\ a Second Department of Cardiac Surgery, Key Laboratory on Assisted Circulation of Health Ministry, and \\ ${ }^{\text {b}}$ Department of Anesthesiology, Heart Center, 1st Affiliated Hospital, Sun Yat-sen University, Guangzhou, China
}

For editorial comment see p. 241

\section{Key Words}

Deep hypothermia circulatory arrest · Cerebral injury .

Neuroinflammation - Endogenous neuroprotection .

Toll-like receptor $\cdot$ Nuclear factor-kappa B $\cdot$ Interleukin-6

\begin{abstract}
Objectives: The alteration of the Toll-like receptor/nuclear factor-kappa B (TLR4/NF-KB) signaling pathway during deep hypothermia circulatory arrest (DHCA) has not yet been defined. The aim of this study was to explore the expression of the TLR4/NF-KB pathway cytokine in cerebral injury resulting from DHCA as well as the effect of selective antegrade cerebral perfusion (SACP) on TLR4/NF-KB pathway expression. Methods: Twelve pigs were randomly assigned to DHCA alone $(n=6)$ or DHCA with SACP $(n=6)$ at $18^{\circ} \mathrm{C}$ for $80 \mathrm{~min}$. Serum interleukin (IL)- 6 was assayed by ELISA. Apoptosis and NF-KB proteins were detected by fluorescence TUNEL and Western blot, respectively. The level of TLR4 mRNA and protein were determined through qRT-PCR and Western blot. Results: The serum IL- 6 level of the SACP group was significantly lower than that of the DHCA group at the end of circulation arrest and experimentation. Apoptotic index and NF-KB protein were apparently lower in SACP animals $(p<$ 0.05). Compared to the DHCA group, the levels of TLR4 pro-
\end{abstract}

\section{KARGER}

E-Mail karger@karger.com

www.karger.com/crd tein and mRNA in the SACP group were lower with significance $(p<0.05)$. Conclusions: The TLR4/NF-KB signaling pathway plays a critical role in the pathogenesis of DHCA cerebral injury. Attenuation of the TLR4/NF-KB inflammatory cytokines probably contributes to the neuroprotective effect of SACP. The TLR4/NF-KB inflammatory signaling pathway may be a novel therapeutic target for developing a new strategy for neuroprotection in DHCA.

(C) 2014 S. Karger AG, Basel

\section{Introduction}

Deep hypothermic circulatory arrest (DHCA) has been frequently used in cardiac surgery since it was introduced by Griepp in 1975 [1]. Despite its effectiveness in reducing mortality, DHCA inevitably leads to neuropsychiatric complications, e.g. neurological dysfunction, either temporary or permanent, which can be one of the most significant risk factors influencing prognosis [2]. The maximum DHCA interval is approximately $80 \mathrm{~min}$. Prolonged DHCA (100 min in recent clinical reports $[3,4])$ is associ-

\section{Z.-X.T. and G.-X.C. contributed equally to this article.}

(c) 2014 S. Karger AG, Basel

0008-6312/14/1283-0243\$39.50/0
Zhong-Kai Wu, Second Department of Cardiac Surgery

Key Laboratory on Assisted Circulation of Health Ministry, Heart Center 1st Affiliated Hospital, Sun Yat-sen University, 58 Zhongshan Er Road Guangzhou 510080 (China)

E-Mail wuzhk@mail.sysu.edu.cn 


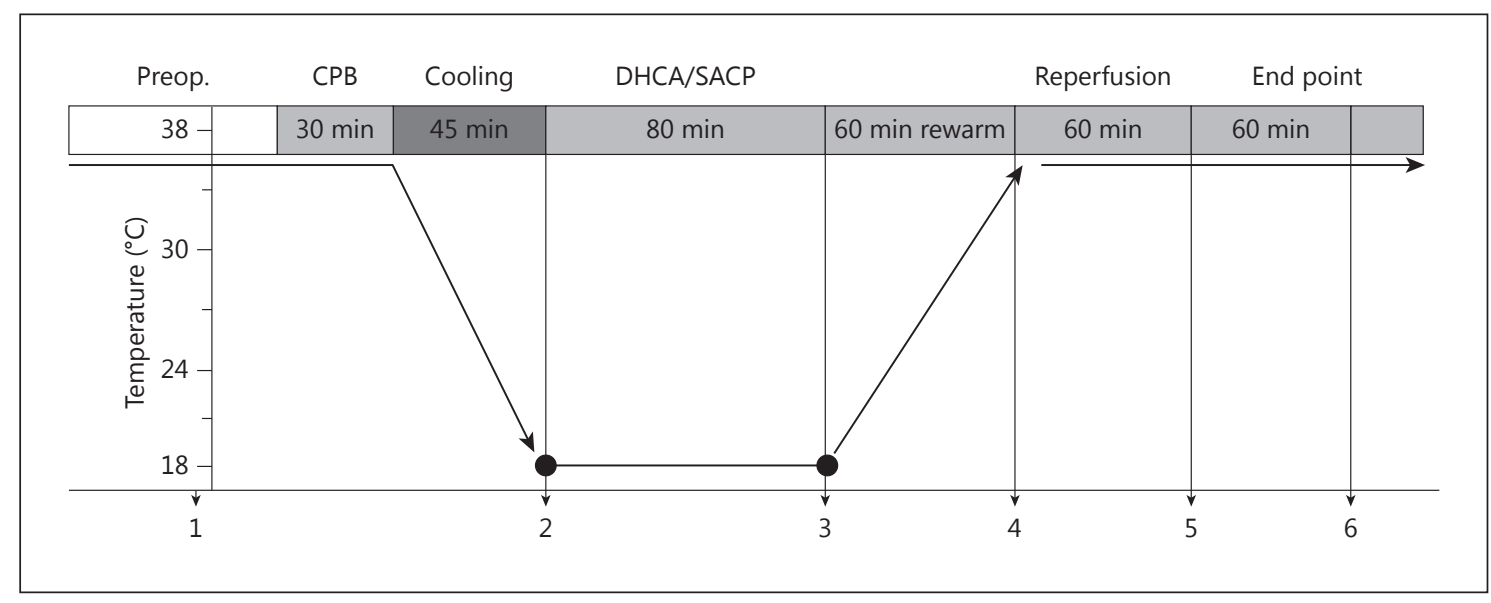

Fig. 1. Schematic diagram of the experimental protocol for this study.

ated with an increased risk of adverse neurological outcomes. For this reason, it is necessary to determine, clinically, which cerebral protection strategy should be adopted preoperatively (especially for prolonged DHCA), such as complex aortic arch reconstruction and congenital heart disease. Other ancillary measures of cerebral protection should be combined with DHCA to minimize its detrimental effects and maximize its benefits. Selective antegrade cerebral perfusion (SACP) is used as a neuroprotection perfusion method during DHCA $[5,6]$.

Although the mechanism of cerebral injury resulting from DHCA has not been fully elucidated, the neuroinflammatory theory is a novel mechanism involved in this process $[7,8]$. It is well documented that Toll-like receptors (TLRs) are the first-line molecules activating innate immune and neuroinflammatory responses. TLR4 is able to activate nuclear factor-kappa B (NF- $\kappa \mathrm{B})$ via mechanisms that are both dependent and independent of the adaptor MyD88 [9]. This pathway leads to the expression of inflammatory cytokine genes, including tumor necrosis factor (TNF)- $a$, interleukin (IL)-1 and IL-6 [10]. There is increasing evidence demonstrating that TLR4 plays a key role in cerebral ischemia [11]. The infarction area, cerebral edema and neurological deficits were improved in TLR4 mutant mice compared with wild-type controls [12]. Nevertheless, there are no data concerning alterations in TLR4/NF- $\mathrm{kB}$ signaling pathway inflammatory cytokines in brain damage following DHCA. In addition, the effect of SACP on the expression of these cytokines remains unknown.

The aim of this study was to explore the expression and the putative role of neuroinflammatory changes induced by TLR4/NF- $\kappa \mathrm{B}$ in cerebral injury following DHCA. We also examined the effect of SACP on this signaling pathway.

\section{Materials and Methods}

\section{Animal Care}

Twelve Wuzhishan miniature pigs (6-8 weeks old and weighing 9.7-13 kg, average $11.66 \mathrm{~kg}$ ) were used in this study. The study was approved by the Institutional Animal Care Committee and was conducted in compliance with the Guide for the Care and Use of Laboratory Animals published by the National Institutes of Health (NIH Publication No. 86-23, revised 1996) and the Guidelines for Animal Experimentation issued by the 1st Hospital which is affiliated to the Sun Yat-sen University.

\section{Study Design}

The animals were randomly assigned to either the DHCA group or the SACP group. The groups were treated with $80 \mathrm{~min}$ of DHCA alone or in conjunction with $80 \mathrm{~min}$ of SACP at $18^{\circ} \mathrm{C}$ and followed by $180 \mathrm{~min}$ of reperfusion including $60 \mathrm{~min}$ of rewarming.

The experimental protocol is described in figure 1. The tag numbers were defined as follows:

(1) Baseline (T1), at a cerebral temperature of $36^{\circ} \mathrm{C}$, immediately before cooling.

(2) After 45 min of cooling (T2), at a nasopharynx/esophagus temperature of $18^{\circ} \mathrm{C}$, before DHCA/SACP.

(3) After 80 min of DHCA/SACP (T3), before the initiation of cardiopulmonary bypass (CPB).

(4) After 60 min of rewarming (T4).

(5) After 120 min of reperfusion (T5).

(6) End point (T6), after 180 min of reperfusion.

Blood was drawn from the animals at every time point. At the final time point, all of the animals were sacrificed in order to harvest the cerebral cortex. 
Anesthesia and Preoperative Management

The animals were anesthetized using an intramuscular administration of $40 \mathrm{mg} / \mathrm{kg}$ ketamine (JiuXu Pharmaceutical Co., Ltd., Zhejiang, China) and $2 \mu \mathrm{g} / \mathrm{kg}$ fentanyl citrate (RenFu Pharmaceutical Co., Ltd., Yichang, China). The animals were incubated and mechanically ventilated at a tidal volume of $15 \mathrm{ml} / \mathrm{kg}$ and a respiratory rate of 16 breaths/min with $40 \%$ oxygen using a volume-cycled respirator (BIRD VELA, Model 606A). Anesthesia was maintained via an intravenous infusion of fentanyl, vecuronium bromide $(0.1 \mathrm{mg} /$ kg, Sida Pharmaceutical Co., Ltd., Hainan, China) and midazolam (0.03 mg/kg, Hua'en Pharmaceutical Co., Ltd., Jiangsu, China).

After intubation, an arterial pressure catheter was inserted into the right femoral artery for pressure monitoring and blood sampling. An 8-Fr central venous catheter was inserted into the left femoral vein for fluid administration and central venous pressure monitoring. Urine output was measured through a suprapubic catheter. Two temperature probes were applied: one inserted into the skull via a drilled hole and one located in the rectum.

\section{Neuromonitoring}

After intubation and the establishment of vascular catheters, the animals were equipped with intracerebral probes. Three small burr holes $(0.8 \mathrm{~mm}$ in diameter) were drilled in three quadrants centered in the bregma of the skull with access to the superficial cerebral cortex (fig. 2).

\section{Cerebral Temperature}

Hole D (fig. 2) was used for taking the cerebral temperature through a microprobe (Licox Integra, Plainsboro, N.J., USA) connected to the transducer of a multichannel physiologic recorder (MP150, BIOPAC Systems, Inc., Calif., USA).

\section{Surgical Procedure and $C P B$}

A median sternotomy was performed, and the strings were sutured. After system heparinization (400 IU/kg intravenously), a 10-Fr aortic cannula (Edwards Life Sciences LLC, Irvine, Calif., USA) was inserted into the ascending aorta for systemic perfusion. In addition, 12-Fr venous cannulas (Edwards Life Sciences LLC) were placed into both the superior and inferior vena cava.

$\mathrm{CPB}$ was performed using two roller pumps for extracorporeal circulation and suction, respectively. The extracorporeal circuit and membrane oxygenator were primed (Minimax Plus Oxygenator SK3301, Medtronic Inc., USA) with multiple electrolyte injections, and heparin ( $3 \mathrm{mg} / 100 \mathrm{ml}$ blood; $3 \mathrm{mg} / 100 \mathrm{ml}$ crystal liquid) was added. CPB flow was maintained at $75-80 \mathrm{ml} / \mathrm{kg} / \mathrm{min}$ with a mean systemic perfusion pressure of $50-80 \mathrm{~mm} \mathrm{Hg}$.

\section{Deep Hypothermia Circulatory Arrest}

The animals were cooled systemically for $45 \mathrm{~min}$ with cardiopulmonary bypass by means of a heat exchanger (Sarns Heater Cooler, Ann Arbor, Mich., USA). After the body temperature was reduced to $30^{\circ} \mathrm{C}$, the ascending aorta was cross-clamped and the cardioplegia solution was administered. A saline ice-slush was topically applied to cool the surface of the heart. The heat exchanger continued to run until the body temperature was cooled to $18^{\circ} \mathrm{C}$. The roller pumps were then turned off, and DHCA was performed for $80 \mathrm{~min}$. After completing the DHCA, the aorta was unclamped, and the animal was rewarmed to normothermia over a 60 -min period using a temperature gradient of $8^{\circ} \mathrm{C}$. For the hearts that resumed deleterious arrhythmia after removing the clamp, direct-

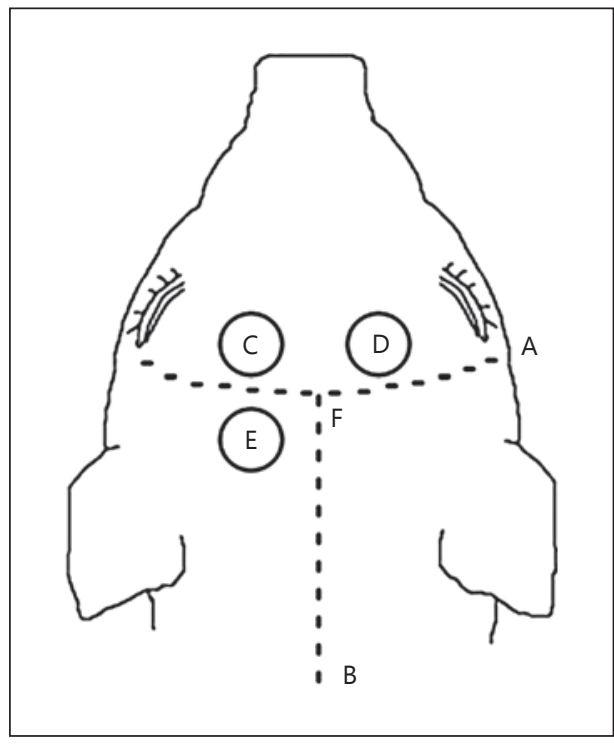

Fig. 2. The skull sketch map for placing probes: A for coronal suture, B for sagittal suture, C for ICP, D for temperature, E for microdialysis and $\mathrm{F}$ for bregma.

current defibrillation was used to restore the sinus rhythm. The animals were weaned from CPB when the hemodynamic data became steady after partial perfusion. The reperfusion lasted for $3 \mathrm{~h}$, and the animals were then sacrificed for tissue harvesting.

\section{Selective Antegrade Cerebral Perfusion}

After reaching the target temperature, the aortic cross was clamped and $\mathrm{CPB}$ was stopped. Passive venous drainage into the blood reservoir was allowed after undergoing DHCA. SACP is dependent on temperature; therefore, blood was allowed to circulate in the heart-lung machine to reach the correct temperature. After $5 \mathrm{~min}, \mathrm{SACP}$ was initiated through a 6-Fr catheter inserted into the innominate artery and was maintained at the same temperature for $80 \mathrm{~min}$. The innominate artery was snared to minimize blood loss. The perfusion pressure was controlled at $40-50 \mathrm{~mm} \mathrm{Hg}$ at a rate of $10 \mathrm{ml} / \mathrm{kg} / \mathrm{min}$. At the end of the 80 -min DHCA period, the snare on the innominate artery was released and complete CPB was gradually restored. The animals were warmed until reaching a cerebral temperature of $36^{\circ} \mathrm{C}$.

\section{Tissue Harvesting}

After $3 \mathrm{~h}$ of reperfusion, the skull was carefully opened and the frontal cortex was quickly removed. The tissue was fixed for $24 \mathrm{~h}$ either in $10 \%$ buffer paraformaldehyde solution or $2.5 \%$ glutaraldehyde in $0.1 \mathrm{M}$ sodium cacodylate $(\mathrm{pH} 7.4)$ at $4^{\circ} \mathrm{C}$ for $24 \mathrm{~h}$ for subsequent fluorescence TUNEL or else immediately snap frozen in liquid nitrogen. The samples were stored at $-80^{\circ} \mathrm{C}$ for Western blot and qRT-PCR.

\section{Biochemical Analysis}

The serum IL-6 (P600B, Quantikine, R\&D Systems, Inc.) concentration was determined with an immunoassay analyzer (Cobas e 601, Roche) using the ELISA method. 


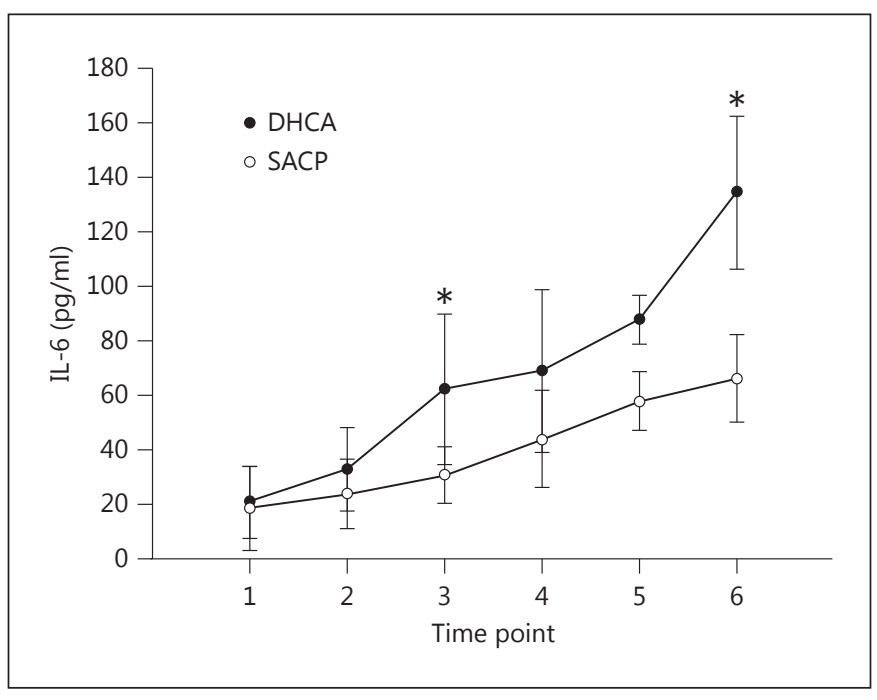

Fig. 3. The serum IL-6 level of the DHCA group and SACP group was examined by ELISA analysis. ${ }^{*} \mathrm{p}<0.05$.

\section{Hematoxylin and Eosin Staining}

Each section was deparaffinized in xylene, and the sections were dehydrated with a graded alcohol series. After being counterstained with hematoxylin for $2 \mathrm{~min}$, the sections were incubated in the eosin staining solution for $1 \mathrm{~min}$. They were washed in distilled water for 3 min after each staining, and then dehydrated with absolute alcohol followed by xylene. They were air-dried and coverslipped with Permount. All specimens were observed and photographed using a microscope by an experienced pathologist who was blind to the study design.

\section{Fluorescence TUNEL}

After deparaffinizing the sections in xylene for $5 \mathrm{~min}$, they were hydrated with $100 \%$ ethanol for $3 \mathrm{~min}$ and $95 \%$ ethanol for $1 \mathrm{~min}$. They were then incubated with proteinase $\mathrm{K}(20 \mu \mathrm{g} / \mathrm{ml}$ in $10 \mathrm{mM}$ Tris/HCl, pH 7.4) for $30 \mathrm{~min}$. The sections were treated with TdT Reaction Mixture for $60 \mathrm{~min}$ and then stained with Hoechst for 10 min at $37^{\circ} \mathrm{C}$ in a humidified chamber. The samples were rinsed with PBS for 2 min after each staining step. A positive result was confirmed when the nuclei stained brown. To quantify apoptotic cells, sections were examined at a magnification of $\times 10-40$, using a Zeiss eyepiece graticule with a 100 -square grid. Apoptotic neurons were counted in 10 different fields in each region at $\times 40$ magnification using defined areas in the cortex. The investigator who analyzed the TUNEL sections was blind to the group identities. Apoptotic neurons were expressed as an apoptotic index (AI) that was calculated using the equation: $\mathrm{AI}=$ apoptotic neurons/total neurons $\times 100 \%$.

\section{Quantitative Real-Time RT-PCR}

Total RNA was isolated from tissue samples with Trizol (Invitrogen) according to the manufacturer's instructions. RNA was reverse-transcribed using a ReverTra Ace qPCR RT kit (Toyobo Biochemicals, Osaka, Japan) according to the manufacturer's protocol. Sequence-specific primers for Sus scrofa TLR4 and $\beta$-actin are as follows: TLR4-F: 5'-CTTCACTACAGAGACTTCATTC-3', TLR4-R: 5'-ACACCACGACAATAACCT-3', actin-F: 5' ${ }^{\prime}$-TGTTGACAATGGATCCGGTA- ${ }^{\prime}$ and actin-R: $5^{\prime}$-CTGCTGGAAGGTGGAGAGAG-3'.

Real-time PCR was performed with a SoFast EvaGreen Supermix Kit (Bio-Rad, Hercules, Calif., USA) on a Bio-Rad Q5 instrument (Bio-Rad) using the SyBr Green detection protocol described by the manufacturer. Briefly, the amplification mixture consisted of $0.4 \mu \mathrm{M}$ primers, $10 \mu \mathrm{l}$ of SsoFast EvaGreen supermix (Bio-Rad) and $2 \mu \mathrm{l}$ of template DNA in a total volume of $20 \mu \mathrm{l}$. The samples were amplified with the following program: initial denaturation at $98^{\circ} \mathrm{C}$ for $2 \mathrm{~min}$, followed by 40 cycles of denaturation for $5 \mathrm{~s}$ at $98^{\circ} \mathrm{C}$ and annealing/elongation for $30 \mathrm{~s}$ at $57^{\circ} \mathrm{C}$. The fluorescence signals were continuously collected. All PCR reactions were performed in triplicate, and control reactions without a template were included. TLR4 mRNA expression levels were normalized and calculated with a standard curve using actin as the reference gene.

\section{Western Blot}

Total proteins were extracted by homogenizing samples in RIPA buffer (Sangon, Shanghai, China). The protein concentration was determined with a BCA protein assay kit (Sangon). The proteins were boiled with $4 \times$ SDS loading buffer and separated by $10 \%$ sodium dodecyl sulfated-polyacrylamide gel electrophoresis and then transferred to nitrocellulose membranes (Pall, New York, N.Y., USA) using the Mini Trans-Blot electrophoretic transfer cell system (Bio-Rad). The membranes were blocked for $2 \mathrm{~h}$ at room temperature with 5\% nonfat milk in Tris-buffered saline Tween 20 (NaCl, 0.1\% Tween-20, Tris). NF-kB/P65 (Abcam, ab31481, 1:1,000) and TLR4 (Abcam, ab8376, 1:1,000) were incubated overnight at $4^{\circ} \mathrm{C}$. The primary antibody was detected with a $1: 4,000$ dilution of peroxide-conjugated goat anti-piglet IgG (Zymed) for $1 \mathrm{~h}$ at room temperature. The protein bands were visualized with an ECL plus Western blot detection system (Forevergen) on X-ray film (Kodak, Rochester, N.Y., USA). The same membranes were also blotted with GAPDH $(1: 1,000)$ and H3 (Bioss, bs-0349R, 1:500) antibodies. Densitometry was performed using Kodak Molecular Imaging software.

\section{Statistical Analysis}

All statistical analyses were performed using SPSS 20.0 for Windows software (IBM SPSS, USA). Continuous variables are expressed as the mean \pm standard deviation. ANOVA and Student's unpaired t test were used to evaluate significance for continuous variables at different time points in the same group or at the same time point between different groups. Student's unpaired $t$ test was also applied to assess the differences in the qRT-PCR and Western blot results from both groups. $\mathrm{p}<0.05$ was defined as statistically significant.

\section{Results}

\section{Biochemical Analysis}

ELISA analysis demonstrated that the serum IL-6 levels of the SACP group were significantly lower than those of the DHCA group at T3 and T6 (p < 0.05; fig. 3 ). 
Fig. 4. a DHCA group: a few inflammatory cells surrounded the vasculature like a sleeve (yellow arrow; color refers to the online version only), and liquefaction necrosis was observed. b SACP group: very little vascular dilatation and congestion were observed. Inflammatory cells were not obvious. HE. $\times 10-40$.
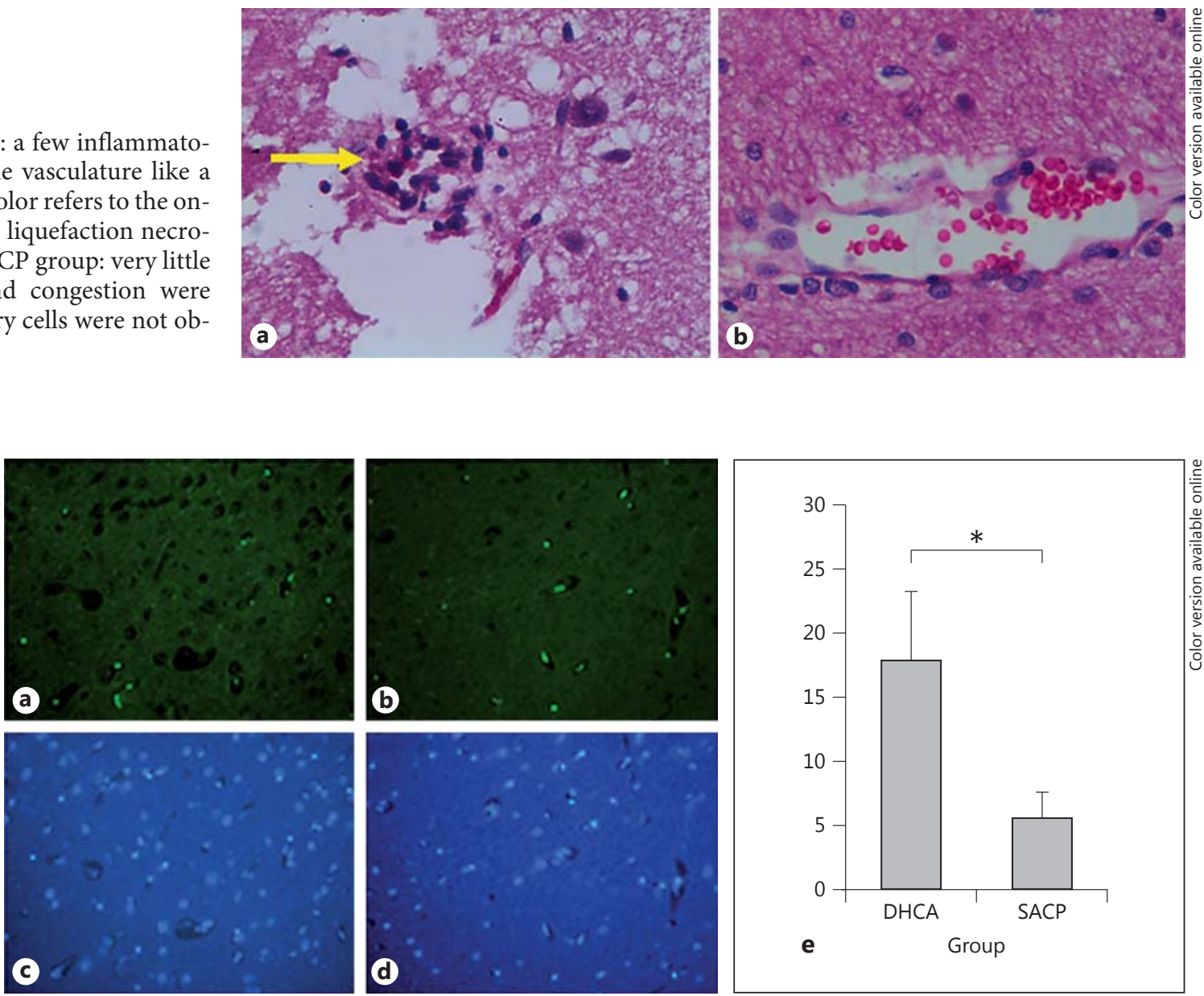

Fig. 5. Fluorescence staining of the frontal cortex. a, b TUNEL. c, d Hoechst. $\times 400$. a, $\mathbf{c}$ DHCA group. b, d SACP group. a More positive staining was seen in the nuclei of neurons. $\mathbf{b}$ Staining was less positive. e AI calculated in the DHCA and SACP groups (17.89 \pm 5.35 vs. $9.66 \pm 1.97, \mathrm{t}=3.319) .{ }^{*} \mathrm{p}=0.02$.

\section{Hematoxylin and Eosin Staining}

At a high magnification $(\times 400)$, most of the vasculature was dilated and congested and was surrounded by inflammatory cells. Liquefaction necrosis was observed in DHCA animals (fig. 4a). A milder vascular dilatation and congestion were observed, and the inflammatory cells were not obvious in the SACP-treated animals (fig. $4 b$ ).

\section{Fluorescence TUNEL}

There were more TUNEL-positive nuclei in the DHCA-treated cerebral cortex neurons (fig. 5a) than in the SACP group (fig. 5b). The AI of the DHCA group was significantly higher than that of the SACP group (17.89 \pm 5.35 vs. $9.66 \pm 1.97, t=3.319, \mathrm{p}=0.02$; fig. $5 \mathrm{e}$ ).

\section{Quantitative Real-Time RT-PCR}

The TLR4 mRNA levels of the SACP animals were significantly lower than those of the DHCA animals $(\mathrm{t}=$ $3.09, \mathrm{p}=0.023$; fig. 6 ).

\section{Western Blot}

The protein levels of NF- $\mathrm{BB} / \mathrm{P} 65$ and TLR4 were significantly lower in the SACP group than in the DHCA group $(\mathrm{t}=3.89, \mathrm{p}=0.037$; fig. 7$)$.

\section{Discussion}

Among all the molecular signaling pathways participating in the neuroinflammatory cascade, TLR4 was the first to be discovered and it is the TLR that has been studied the 


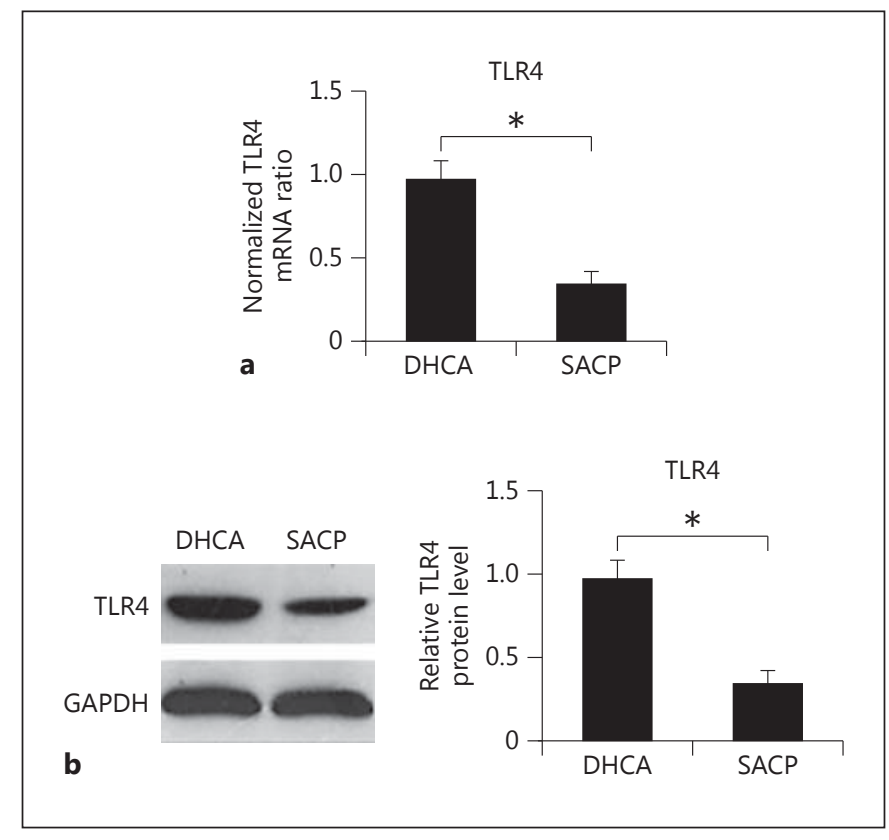

Fig. 6. TLR4 mRNA and protein levels were detected in the cerebral cortex from both groups by qRT-PCR and Western blot, respectively. a TLR4 mRNA. b Protein. ${ }^{*} \mathrm{p}<0.05$.

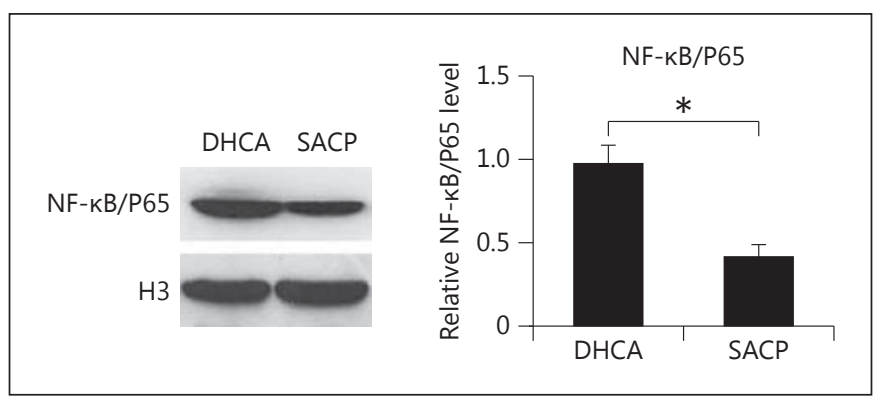

Fig. 7. Western blot was used to measure the expression of NF- $\kappa \mathrm{B} /$ $\mathrm{P} 65$ protein in the animals treated by DHCA or SACP. ${ }^{*} \mathrm{p}<0.05$.

most. TLR4 plays a key role in innate immunity in the central nervous system [13] and cardiovascular system [14, 15]. Increased TLR4 expression levels of mRNA and proteins have been observed in heart tissue sampled from patients with dilated cardiomyopathy and atherosclerosis as well as in murine hearts exposed to ischemic injury $[14,15]$.

Substantial evidence indicates that TLR4 is a crucial factor for the central nervous system, not only in neurodegenerative diseases (e.g. Alzheimer's disease) and brain trauma but also in hypoxia-associated diseases and cerebrovascular diseases (e.g. stroke) $[11,16,17]$. The pathogenic role of TLR4 in cerebral ischemia was established in TLR4 mutant mice with transient middle cerebral artery occlusion (MCAO). The infarction area, cerebral edema and neurological behavioral scores were improved in TLR4 mutant mice compared to wild-type animals [12]. Another study utilizing TLR4 mutant mice examined global cerebral ischemia reperfusion. The study showed ameliorated neuronal injury and apoptosis and reduced secretion of proinflammatory cytokines [18]. Recently, Yao et al. [19] reported that the microglia protein level of TLR4 was markedly enhanced in the corpus callosum and cerebellum from rats subjected to hypoxia. In our study, histology examinations show that there was evidence of cerebral injury and neuroinflammation. We found that both the mRNA and protein expression levels of TLR4 simultaneously increased in the DHCA group. This result suggests that TLR4 is involved in the mechanism of brain damage caused by DHCA. Attenuating the activation of TLR4 by SACP is one mechanism for inducing a neuroprotective effect. To our knowledge, this is the first report showing a change in the TLR4 signaling pathway during cerebral injury. We demonstrated that SACP is able to attenuate the TLR4/NF- $\kappa B$ inflammation axis and cytokine expression in a DHCA pig model.

$\mathrm{NF}-\kappa \mathrm{B}$ is a central mediator of inflammatory cascades. Abundant evidence demonstrates that NF- $\mathrm{KB}$ is activated in brain ischemia $[9,20]$. Increased activity of NF- $\kappa B$ was examined in a transient MACO model [21]. A decreased infarction volume induced by transient and permanent ischemia was reported in mice deficient in the P50 subunit of NF- $\kappa B[21,22]$. Furthermore, reduced NF- $\kappa B$ levels were detected in TLR4 knockout mice receiving transient MACO treatment [18]. It is still unclear whether the function of NF- $\kappa \mathrm{B}$ is proapoptotic or antiapoptotic [20, 21]. Our results indicate a proapoptotic function of NF$\kappa \mathrm{B}$ in cerebral injury induced by DHCA based on the high AI. Furthermore, SACP might protect the brain from injury by reducing apoptosis and inflammatory changes. The mechanism may be via suppressing the activity of $\mathrm{NF}-\kappa \mathrm{B}$, which is a key factor for neuroinflammation.

A recent clinical trial reported that there was a correlation between serum IL-6 and cardiovascular pathology [23]. In the brain, the upregulation of IL- 6 through NF$\kappa \mathrm{B}$ plays a key role in activating microglia, initiating the infiltration of immune cells and triggering a series of events that ultimately lead to neuronal damage $[9,20]$. The level of proinflammatory cytokines such as TNF- $\alpha$ and IL-6 in TLR4-null mice was lower than that in wildtype controls [24]. Our experimental data showed that the serum IL-6 levels clearly increased in the DHCA group and were decreased in the SACP group. This result fur- 
ther supports the severe neuroinflammatory evidence in cerebral injury caused by DHCA.

We are aware of the limitations of this study. First and foremost, there were no postoperative data relevant to cerebral function recovery, such as neurological behavioral scores. This study aimed to explore brain injury associated with acute ischemia rather than chronic cases, and postoperative variables were beyond its scope. In addition, inhibitor or enhancer agents of TLR4/NF- $\kappa B$ were not applied in this experiment to elucidate the mechanism of the TLR4/NF- $\mathrm{kB}$ signaling axis. This is our first study based on a large animal model; these limitations will be taken into consideration in a further study.

\section{Conclusion}

These findings suggest that the TLR4/NF- $\kappa \mathrm{B}$ signaling axis plays an important role in the neuroinflammation mechanism of cerebral injury resulting from DHCA.
SACP exhibits a neuroprotective effect by improving the histology and lowering the AI. These changes contribute to the attenuation of the TLR4/NF- $\kappa B$ signaling pathway mediators, including upstream factors (TLR4/NF- $\kappa B$ ) and downstream cytokines (IL-6). The neuroprotective effect of SACP may be regulated in part by the TLR4/NF$\kappa \mathrm{B}$ signaling pathway. Therefore, the TLR4/NF- $\kappa \mathrm{B}$ signaling pathway represents a novel endogenous therapeutic target.

\section{Acknowledgments}

The authors deeply acknowledge the expert assistance of Gang Dai, Rong Fang and other researchers at the Key Assisted Circulation Lab of the 1st Affiliated Hospital, Sun Yat-sen University. This research was funded by the National Basic Research Program of China (973 Program, No. 2010CB5295007) from the Ministry of Science and Technology of the People's Republic of China, Pearl River Scholar Program (80000-3210003) and by the National Science Fund for Young Scholars (81000061).

\section{References}

1 Griepp RB, Stinson EB, Hollingsworth JF, Buehler D: Prosthetic replacement of the aortic arch. J Thorac Cardiovasc Surg 1975;70: 1051-1063.

2 Givehchian M, Beschorner R, Ehmann C, Frauenlob L, Morgalla M, Hashemi B, Ziemer G, Scheule AM: Neuroprotective effects of erythropoietin during deep hypothermic circulatory arrest. Eur J Cardiothorac Surg 2010; 37:662-668.

3 Zierer A, Detho F, Dzemali O, Aybek T, Moritz A, Bakhtiary F: Antegrade cerebral perfusion with mild hypothermia for aortic arch replacement: single-center experience in 245 consecutive patients. Ann Thorac Surg 2011; 91:1868-1873.

4 Pacini D, Leone A, Di Marco L, Marsilli D, Sobaih F, Turci S, Masieri V, Di Bartolomeo $\mathrm{R}$ : Antegrade selective cerebral perfusion in thoracic aorta surgery: safety of moderate hypothermia. Eur J Cardiothorac Surg 2007;31: 618-622.

5 Coselli JS, LeMaire SA: Experience with retrograde cerebral perfusion during proximal aortic surgery in 290 patients. J Card Surg 1997; 12:322-325.

6 Khaladj N, Peterss S, Oetjen P, von Wasielewski R, Hauschild G, Karck M, Haverich A, Hagl C: Hypothermic circulatory arrest with moderate, deep or profound hypothermic selective antegrade cerebral perfusion: which temperature provides best brain protection? Eur J Cardiothorac Surg 2006;30:492-498.
7 Drury PP, Bennet L, Gunn AJ: Mechanisms of hypothermic neuroprotection. Semin Fetal Neonatal Med 2010;15:287-292.

8 Kerendi F, Kirshbom PM, Halkos ME, Wang NP, Kin H, Jiang R, Zhao ZQ, Kanter KR, Guyton RA, Vinten-Johansen J: Thoracic Surgery Directors Association Award. Cobalt chloride pretreatment attenuates myocardial apoptosis after hypothermic circulatory arrest. Ann Thorac Surg 2006;81:2055-2062.

-9 Shichita T, Sakaguchi R, Suzuki M, Yoshimura A: Post-ischemic inflammation in the brain. Front Immunol 2012;3:132.

10 Akira S, Takeda K: Toll-like receptor signalling. Nat Rev Immunol 2004;4:499-511.

11 Hamanaka J, Hara H: Involvement of Tolllike receptors in ischemia-induced neuronal damage. Cent Nerv Syst Agents Med Chem 2011;11:107-113.

12 Poltorak A, He X, Smirnova I, Liu MY, Van Huffel C, Du X, Birdwell D, Alejos E, Silva M, Galanos C, Freudenberg M, Ricciardi-Castagnoli P, Layton B, Beutler B: Defective lps signaling in $\mathrm{C} 3 \mathrm{H} / \mathrm{HeJ}$ and $\mathrm{C} 57 \mathrm{BL} / 10 \mathrm{ScCr}$ mice: mutations in TLR4 gene. Science 1998; 282:2085-2088.

13 Lehnardt S, Lachance C, Patrizi S, Lefebvre S, Follett PL, Jensen FE, Rosenberg PA, Volpe JJ, Vartanian T: The Toll-like receptor TLR4 is necessary for lipopolysaccharide-induced oligodendrocyte injury in the CNS. J Neurosci 2002;22:2478-2486.
14 Frantz S, Kobzik L, Kim YD, Fukazawa R, Medzhitov R, Lee RT, Kelly RA: Toll4 (TLR4) expression in cardiac myocytes in normal and failing myocardium. J Clin Invest 1999;104: 271-280.

15 Bielinski SJ, Hall JL, Pankow JS, Boerwinkle E Matijevic-Aleksic N, He M, Chambless L, Folsom AR: Genetic variants in TLR2 and TLR4 are associated with markers of monocyte activation: the atherosclerosis risk in communities MRI study. Hum Genet 2011;129:655662.

16 Song M, Jin J, Lim JE, Kou J, Pattanayak A, Rehman JA, Kim HD, Tahara K, Lalonde R, Fukuchi K: TLR4 mutation reduces microglial activation, increases $A \beta$ deposits and exacerbates cognitive deficits in a mouse model of Alzheimer's disease. J Neuroinflamm 2011; 8:92.

17 Chen CC, Hung TH, Wang YH, Lin CW, Wang PY, Lee CY, Chen SF: Wogonin improves histological and functional outcomes, and reduces activation of TLR4/NF- $\mathrm{BB}$ signaling after experimental traumatic brain injury. PLoS One 2012;7:e30294.

18 Hua F, Ma J, Ha T, Xia Y, Kelley J, Williams DL, Kao RL, Browder IW, Schweitzer JB, Kalbfleisch JH, Li C: Activation of Toll-like receptor 4 signaling contributes to hippocampal neuronal death following global cerebral ischemia/reperfusion. J Neuroimmunol 2007; 190:101-111.
Effect of DHCA and SACP on TLR4

Pathway Expression 
19 Yao L, Kan EM, Lu J, Hao A, Dheen ST, Kaur C, Ling EA: Toll-like receptor 4 mediates microglial activation and production of inflammatory mediators in neonatal rat brain following hypoxia: role of TLR4 in hypoxic microglia. J Neuroinflamm 2013;10:23.

20 Ridder DA, Schwaninger M: NF- $\kappa B$ signaling in cerebral ischemia. Neuroscience 2009;158: 995-1006.

-21 Schneider A, Martin-Villalba A, Weih F, Vogel J, Wirth T, Schwaninger M: NF-kB is activated and promotes cell death in focal cerebral ischemia. Nat Med 1999;5:554559.

22 Nurmi A, Lindsberg PJ, Koistinaho M, Zhang W, Juettler E, Karjalainen-Lindsberg ML, Weih F, Frank N, Schwaninger M, Koistinaho J: Nuclear factor-kappaB contributes to infarction after permanent focal ischemia. Stroke 2004;35:987-991.

23 Danesh J, Kaptoge S, Mann AG, Sarwar N, Wood A, Angleman SB, Wensley F, Higgins
JP, Lennon L, Eiriksdottir G, Rumley A, Whincup PH, Lowe GD, Gudnason V: Longterm interleukin-6 levels and subsequent risk of coronary heart disease: two new prospective studies and a systematic review. PLoS Med 2008;5:e78

24 Cao CX, Yang QW, Lv FL, Cui J, Fu HB, Wang JZ: Reduced cerebral ischemia-reperfusion injury in Toll-like receptor 4 deficient mice. Biochem Biophys Res Commun 2007; 353:509-514. 